\title{
NeW DeCiSion MeTHOdOLOGY FOR SELECTING MANUFACTURING CODES OF NUCLEAR REACTOR Pressure-VeSSElS
}

\author{
Álvaro Rodríguez-Prieto, Ana María Camacho, Miguel Ángel Sebastián \\ Department of Manufacturing Engineering, UNED, Juan del Rosal 12, Madrid 28040, Spain
}

\begin{abstract}
An innovative methodology based on stringency matrixes is proposed in this paper as a decision tool among materials specifications; thus, this selection method helps in the stage of the structural materials selection used in the reactor pressure vessels (RPV) manufacturing. This paper quantifies the stringency of materials requirements by application of a decision deterministic algorithm based on a stringency matrixes system. The methodology has been applied to different standardized materials used in nuclear design, such as SA - 533 Grade B Cl.1, SA - 508 Cl.3 (specified by American society of mechanical engineers - ASME code), DIN 20MnMoNi55 (as described in KTA rules) and 16MND5 (issued by French nuclear commission, RCC-MR code) specifications. Key scientific publications on the influence of chemical composition on the mechanical behaviour of materials have been considered as an additional element of judgement. The final results show that steel specified by KTA is the best option.
\end{abstract}

Keywords: Decision methodology; stringency matrix; manufacturing codes; reactor pressure vessel, nuclear materials
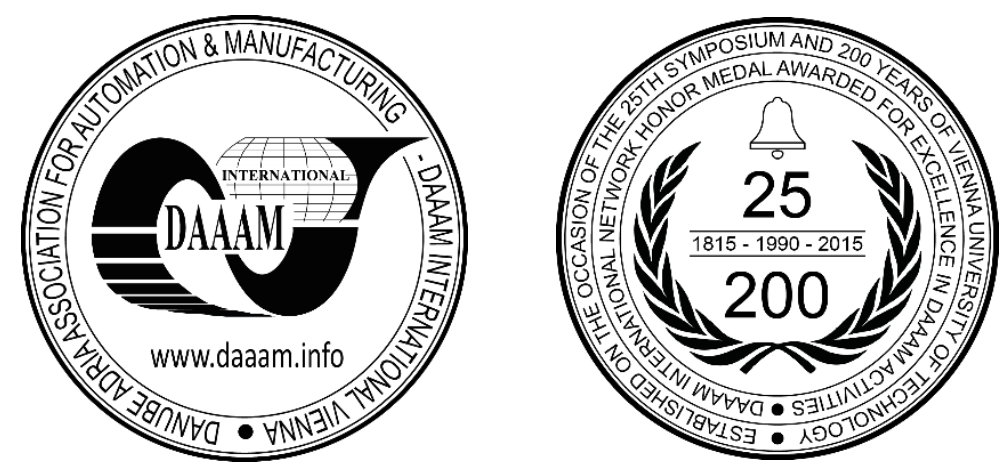

This Publication has to be referred as: Rodríguez Prieto, A[lvaro]; Camacho Lopez, A[na] M[aría] \& Sebastian, M[iguel] A[ngel] (2016). New Decision Methodology for Selecting Manufacturing Codes of Nuclear Reactor PressureVessels, Proceedings of the 26th DAAAM International Symposium, pp.0693-0698, B. Katalinic (Ed.), Published by DAAAM International, ISBN 978-3-902734-07-5, ISSN 1726-9679, Vienna, Austria DOI: $10.2507 / 26$ th.daaam.proceedings.095 


\section{Introduction}

The objective of the structural design is to create engineering components that safely accomplishes their function [1]. In case of pressurized water reactors, severe accidents are the accidents associated with significant core damage [2]. Technological requirements described by equivalent specifications sometimes exhibit significant differences between them. Additionally, publications of key importance about the influence of the chemical composition on the mechanical behaviour of materials have not been typically considered to elaborate those requirements [3]. This paper presents an innovative methodology based on stringency matrixes, as a decision algorithm, that improves the current selection method for structural materials used in the reactor pressure vessels (RPV) manufacturing. Thus, the aim of this research is to perform a quantitative analysis of technological requirements of materials used in the manufacture of reactor pressure vessels. ASME B\&PV (American society of mechanical engineers code) code technological requirements, KTA (German nuclear commission code) and RCC-MR (French nuclear code) ones are analyzed. It is a proven fact that the effect of neutron flux on the brittle behavior of the material is a complex phenomenon dependent on the alloy composition and temperature [4-6]. In particular, the percentage of copper, phosphorus and nickel are considered important parameters for the irradiation embrittlement [7]; in addition, vanadium affects negatively the mechanical properties of irradiated materials $[8,9]$. For standard operating conditions of the reactor, the chemical composition is more influential in the process of neutron irradiation embrittlement [10] than neutron flux [11] and irradiation temperature [12, 13].

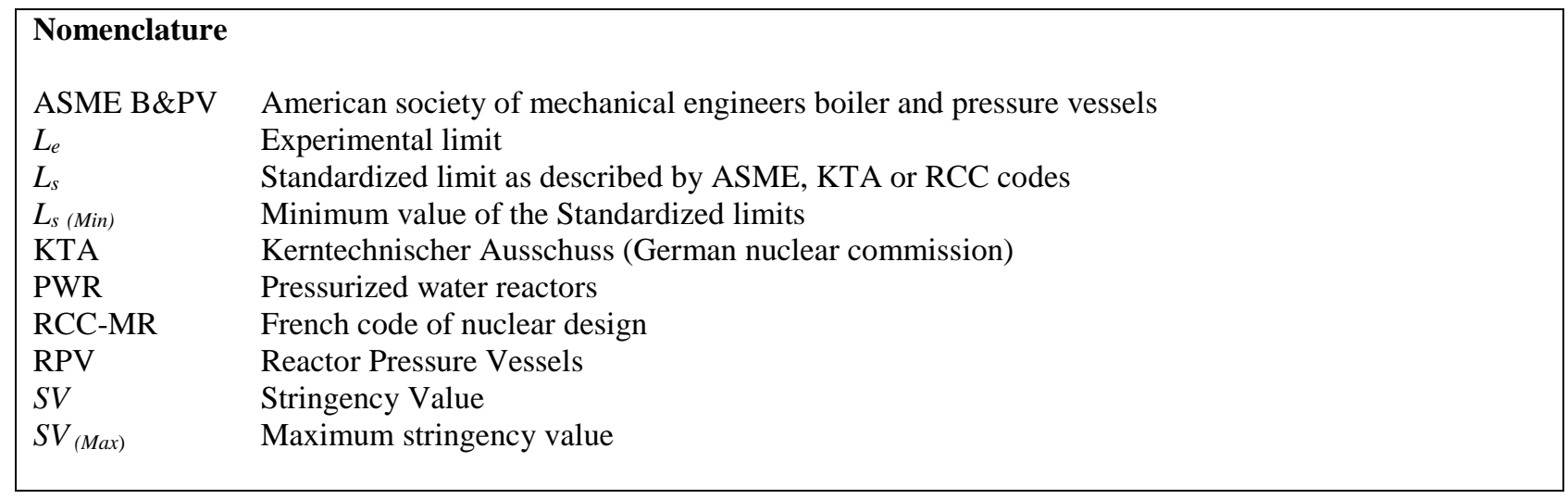

\section{Methodology and initial considerations}

The methodology is based on the definition and use of stringency values (SV), as a novel quantification tool of the stringency of the most relevant technological requirements described by international manufacturing codes. Fig. 1 shows a new decision deterministic algorithm to evaluate the main requirements described by American society of mechanical engineers (ASME), German nuclear commission (KTA) and the French nuclear commission (RCC-MR).

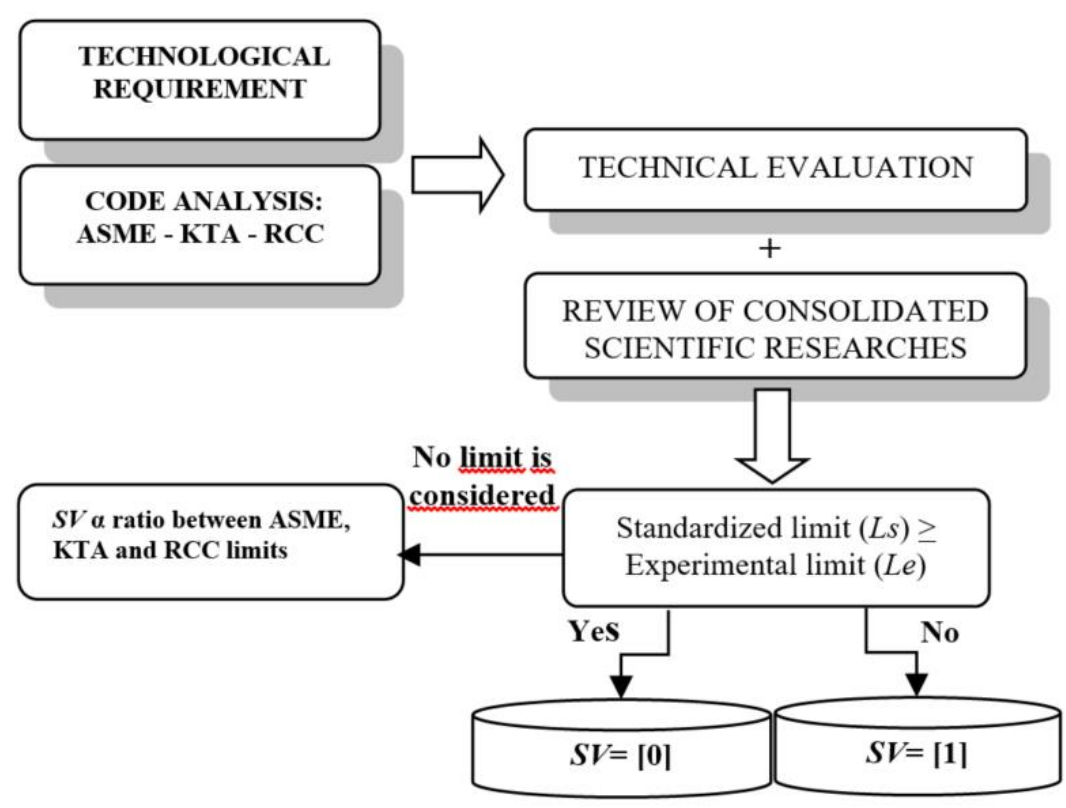

Fig.1. A decision algorithm: methodology to obtain the stringency value (SV) 
The evaluation process consists of assigning a stringency value $(S V)$ of "1", if standardized requirement $\left(L_{S}\right)$ is less than experimental limit $\left(L_{e}\right)$, and otherwise assigning a stringency value of " 0 " (Eqs. 1-2).

$$
\begin{array}{ll}
S V=0 & \left(L_{s} \geq L_{e}\right) \\
S V=1 & \left(L_{s}<L_{e}\right)
\end{array}
$$

Fig.2 shows stringency value $(S V)$ as a function of the mathematical relation between experimental limit $\left(L_{e}\right)$ and standardized limit $\left(L_{s}\right)$ described by ASME code, KTA rules and RCC-MR code.

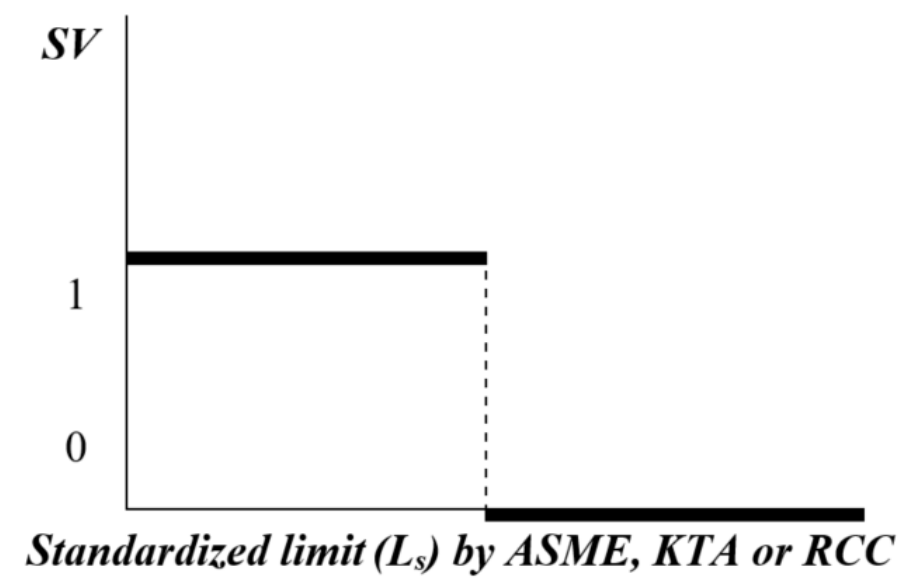

Fig. 2. Stringency value (SV) as a function of the mathematical relation between experimental limit (Le) and standardized limit (Ls)

The mathematical set called "standard limits" is defined as the set of maximum values indicated by specifications [14]. This set is designed as $\{L s$ (ASME, KTA, RCC) $\}$. Thus, equations 3-4 are used when no experimental limit $\left(L_{e}\right)$ is considered to evaluate impurities content:

$$
S V=1 \text { for } \min \{L s(\mathrm{ASME}, \mathrm{KTA} \text { and RCC })\}
$$

The stringency levels of the rest of standard requirements are calculated according to equation 4 :

$$
S V=\frac{L_{s(\text { Min })}}{L_{s}} S V_{\text {Max }}
$$

Where $\mathrm{SV}_{\mathrm{Max}}$ is equal to 1.

Once requirements are analyzed and the valuation methodology is applied, the next step consists of creating the stringency matrixes (SM) for ASME code, KTA rules and RCC-MR code.

\section{[Requirement 1 Requirement 3$]$ \\ Requirement 4 Requirement 2$]$}

Copper, nickel, phosphorous and vanadium have been considered as the most influential elements because they increase the susceptibility to the irradiation embrittlement. Therefore, the matrix is configured as follows:

$$
\left[\begin{array}{cc}
S V(C u) & S V(P) \\
S V(V) & S V(N i)
\end{array}\right]
$$

Finally, the absolute value of the determinant of each matrix is calculated according to equation 5.

$$
S M=[S V(C u) \cdot S V(N i)]-[S V(P) \cdot S V(V)]
$$

And the final values are compared and discussed. It can be seen as a single severity value (SV) equal to zero is sufficient to cancel one of the terms in the equation 5. 


\section{Results and discussion}

\subsection{Previous analysis: review of influence of copper, phosphorous and nickel content}

Previously to application of the evaluation methodology, a rigorous review of key researches about the influence of chemical composition on mechanical behaviour of irradiated RPV steels has been developed. Thus, Odette et al. [15] studied the influence of copper in reactor pressure-vessels steels irradiated by neutron fluxes between $\phi=0.76 \cdot 10^{16}$ $\mathrm{n} / \mathrm{cm}^{2}$ and $\phi=7.1 \cdot 10^{22} \mathrm{n} / \mathrm{cm}^{2}$, at temperatures between $260^{\circ} \mathrm{C}$ and $315^{\circ} \mathrm{C}$. They concluded that a copper content greater than $0.1 \mathrm{wt} \%$ generates copper-rich precipitates that are responsible of irradiation embrittlement in reactor pressure vessel materials [10]. Also, a phosphorus content greater than $0.02 \mathrm{wt} \%$ negatively affects the mechanical properties of the material [16] because it increases the brittleness of the material at higher temperatures. In addition, Petrequin et al. [17], Stofanak et al. [18] and Nikolaeva et al. [19] concluded that no negative effect on the material properties was observed for a nickel content less than $1 \mathrm{wt} \%$. Similarly, vanadium increases the susceptibility of the material to neutron irradiation embrittlement $[8-10,14]$. According to this analysis, Table 1 shows the chemical requirements specified for materials SA-533, SA-508, DIN 20 MnMoNi55 and 16MND5 used in $2^{\text {nd }}$ and $3^{\text {rd }}$ generation of pressurized water reactors (PWR) and the experimental limits $\left(L_{e}\right)$ according to key researches.

\begin{tabular}{|c|c|c|c|c|c|}
\hline \multirow{3}{*}{ Element } & \multicolumn{4}{|c|}{ Chemical requirements } & \multirow{3}{*}{$\begin{array}{c}\text { Experimental } \\
\text { Limit }\left(L_{e}\right)-\mathrm{wt} \% \\
\max \end{array}$} \\
\hline & $\begin{array}{c}\text { SA-533 } \\
\text { (ASME } \\
\text { B\&PV) }\end{array}$ & $\begin{array}{l}\text { SA-508 } \\
\text { (ASME } \\
\text { B\&PV) }\end{array}$ & $\begin{array}{c}\text { DIN } \\
\text { 20MnMoNi55 } \\
\text { (KTA) }\end{array}$ & $\begin{array}{l}\text { 16MND5 } \\
\text { (RCC-MR) }\end{array}$ & \\
\hline & \multicolumn{4}{|c|}{ Maximum values (wt\%) } & \\
\hline $\mathrm{Cu}$ & 0.12 & 0.20 & 0.12 & 0.20 & 0.10 \\
\hline $\mathrm{Ni}$ & 0.73 & 1.00 & 0.85 & 0.80 & 1.00 \\
\hline $\mathrm{P}$ & 0.015 & 0.025 & 0.012 & 0.020 & 0.02 \\
\hline $\mathrm{V}$ & 0.06 & 0.05 & 0.02 & 0.03 & - \\
\hline
\end{tabular}

Table 1. Chemical composition limits specified for studied materials and experimental limits [20-23]

Table 2 presents the stringency values of each requirement for the analyzed specifications. These calculations have been carried out using equations $1-4$.

\begin{tabular}{ccccc}
\hline Specification & $S V(\mathrm{Cu})$ & $S V(P)$ & $S V(N i)$ & $S V(V)$ \\
\hline SA - 533 & 0 & 1 & 1 & 0.33 \\
SA-508 & 0 & 0 & 0 & 0.4 \\
DIN 20MnMoNi55 & 0 & 1 & 1 & 1 \\
16MND5 & 0 & 0 & 1 & 0.67 \\
\hline
\end{tabular}

Table 2. Stringency Value of $\mathrm{Cu}, \mathrm{P}, \mathrm{Ni}$, and V.

It can be observed that DIN 20MnMoNi55 exhibit the most stringent chemical requirements, followed by SA - 533, 16MND5 and SA - 508.

\subsection{Comparison of obtained values}

Table 3 provides the stringency matrixes for ASME code, KTA rules and RCC-MR code, according to equations 1-4.

\begin{tabular}{cccc}
\hline & \multicolumn{2}{c}{ Stringency matrixes } & \\
\hline ASME code & KTA rules & RCC-MR code \\
\hline SA-533 & SA-508 & DIN 20MnMoNi55) & 16MND5 \\
\hline$\left[\begin{array}{cc}0 & 1 \\
0.33 & 1\end{array}\right]$ & {$\left[\begin{array}{cc}0 & 0 \\
0.4 & 0\end{array}\right]$} & {$\left[\begin{array}{ll}0 & 1 \\
1 & 1\end{array}\right]$} & {$\left[\begin{array}{cc}0 & 0 \\
0.67 & 1\end{array}\right]$} \\
\hline
\end{tabular}

Table 3. Stringency matrixes 
In this way, Table 4 provides the absolute value of the calculated determinant of each matrix according to equation 5 .

\begin{tabular}{lc}
\hline \multicolumn{1}{c}{ Specification } & Matrix Determinant \\
\hline SA -533 & 0.33 \\
SA-508 & 0 \\
DIN 20MnMoNi55 & 1 \\
16MND5 & 0 \\
\hline
\end{tabular}

Table 4. Determinant of matrixes (absolute value)

Figure 3 represents the stringency profile obtained.

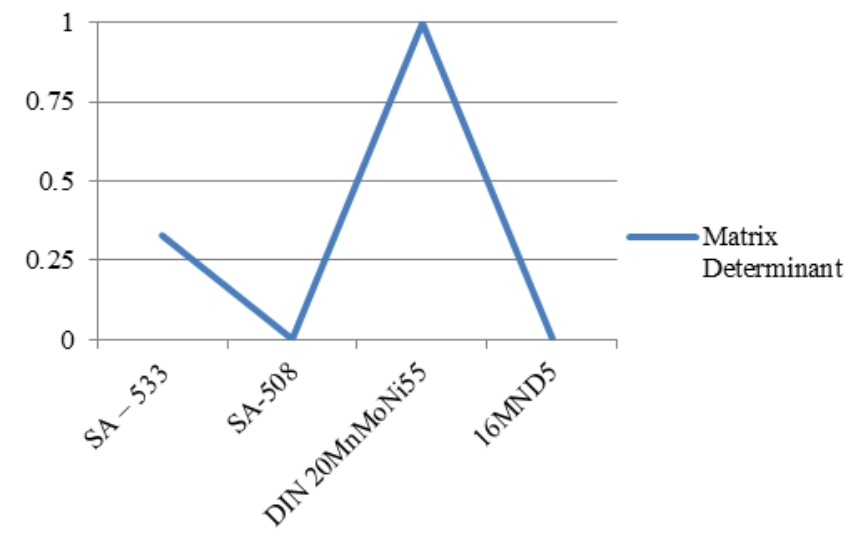

Fig. 3. Final stringency evaluation

On this basis, the best option is the material specified by KTA rules, i.e., DIN 20MnMoNi55. On the other hand, the second best option is the SA-533 Grade B Cl.1 as described by ASME. Finally, we can conclude that SA-508 Cl.3 and 16MND5 exhibit a less stringency of copper, nickel, phosphorous and vanadium requirements with respect to the susceptibility of irradiation embrittlement.

\section{Conclusions and future works}

As a general conclusion, a new methodology to perform a critical evaluation of materials requirements has been developed. This methodology provides an integrated approach that allows objectively evaluating different relevant technological requirements, selected by their influence on mechanical behavior of materials because of the harsh operation conditions. It has been applied to usual materials indicated in ASME, KTA and RCC-MR codes for reactor pressure vessels manufacturing.

The novelty of this new approach lies on the idea of integrating research results in customary engineering projects. In addition, the implementation of this methodology could be suitable to prevent potential failures, providing crucial information to select the most suitable material for the intended application. This methodology based on a quantitative analysis of technological requirements has been applied to materials used in the manufacture of reactor pressure vessels, could extract important conclusions that allow us to select the most suitable standard of material.

The main particular conclusions are the following: the analyzed KTA requirements are more stringent than analyzed ASME and RCC-MR requirements. Specifically, the phosphorous requirements of SA - 508 Cl.3 and 16MND5 are not stringent enough according to the experimental limits; in addition, the nickel requirement of SA $-508 \mathrm{Cl} .3$ is insufficient according to the experimental limits. With respect to the vanadium requirement, DIN $20 \mathrm{MnMoNi55}$ exhibits the highest stringency level. In general, SA-508 Cl.3 and 16MND5 exhibit a less stringency of chemical requirements with respect to the susceptibility of irradiation embrittlement.

Thus, we can conclude that DIN 20MnMoNi55, as described by KTA, provides the best chemical requirements to prevent radiation-induced embrittlement.

The use of this methodology is suitable to prevent potential failures and their consequences for reactor safety. Thus, our wish for the future is applying the stringency matrixes methodology to different standardized specifications used in the manufacture of safety related nuclear components. 


\section{Acknowledgements}

This work has been financially supported by the funds provided through the Annual Grant Call of the E.T.S.I. Industriales of UNED (reference 2014-ICF04)

\section{References}

[1] J. Rajzrová, J. Jiřičková, Severe Accidents Management in PWRs, Procedia Engineering. 69 (2014) 1076 - 1081.

[2] J. Brnic, M.Brcic, Comparison of Mechanical Properties and Resistance to Creep of $20 \mathrm{MnCr5}$ Steel and X10CrAlSi25 Steel, Procedia Engineering. 100 (2015) 84 - 89.

[3] A. Rodríguez, A.M. Camacho, M.A. Sebastián, Prediction of the Mechanical Behaviour of Cladding Materials for Nuclear Reactor Pressure-Vessels Based on the Analysis of Technological Requirements, Procedia Engineering. 100 (2015) $1301-1308$.

[4] A. Ballesteros, R. Ahlstrand, C. Bruynooghe, A. Chernobaeva, Y. Kevorkyan, D. Erak, D. Zurko, Irradiation temperature, flux and spectrum effects, Progress in Nuclear Energy. 53 (2011), 756 - 759.

[5] N. Soneda, K. Dohi, K. Nishida, A. Nomoto, M. Iwasaki M, S. Tsuno, T. Akiyama, S. Watanabe, T. Ohta, Flux effect on neutron irradiation embrittlement of Reactor Pressure Vessel steels irradiated to high fluences, Proceedings of the international symposium on contribution of materials investigations to improve the safety and performance of LWRs, 26 - 30 September, Avignon (France), 2011, A080, pp. 1-9.

[6] M. Serrano, M. Hernández, Research programs of RPV-steels irradiation embrittlement (Programas de investigación sobre fragilización por irradiación de los aceros de vasija), Anales de mecánica y electricidad. 5 (2008) 42-47.

[7] A. Ballesteros, M. Colomer, U. von Estorff, L. Debarberis, The role of pressure vessel embrittlement in the long term operation of nuclear power plants, 38th Annual Meeting Spanish Nuclear Society, 17 - 19 October, Cáceres (España), 2012, 17(5) $1-2$.

[8] CSN, Nuclear physics and technologies (Física y tecnología nucleares), publicaciones del Consejo de Seguridad Nuclear, Madrid, 2012.

[9] J.R. Hawthorne, Significance of selected residual elements to the radiation sensitivity of steels, Nuclear Technology. 59 (1982) 440-455.

[10] A. Rodríguez-Prieto, A.M. Camacho, M.A. Sebastián, Material selection criteria for nuclear power applications: a decision algorithm, JOM: Journal of the Minerals, Metals and Materials Society. DOI: 10.1007/s11837-015-1687$\mathrm{y}$.

[11] T.R. Mager, Radiation embrittlement of nuclear reactor pressure vessels steels: an international review, ASTM Special Technical Publication 1170, 1 (1993) 87-98.

[12] L.F. Porter, Materials in Nuclear Applications, ASTM Special Technical Publication 276, 1 (1981), $147-160$.

[13] M. Kangilaski, The effects of neutron irradiation on structural materials, Battelle Memorial Institute Publications, Columbus, 1967.

[14] A. Rodríguez-Prieto, Analysis of regulated requirements of materials and its influence on reactor pressure-vessels manufacturing for the nuclear industry (Análisis de requisitos tecnológicos de materiales especificados en normativas reguladas y su repercusión sobre la fabricación de recipientes especiales para la industria nuclear), $\mathrm{PhD}$ dissertation, Department of Manufacturing Engineering, UNED, Madrid, 2014.

[15] G.R. Odette, G. Lucas, R. Klingensmith, The influence of metallurgical variables on the temperature dependence of irradiation hardening in pressure vessel steels, ASTM Special Technical Publication 1270, 1 (1996) 606-622.

[16] A.D. Amayev, A.M. Kryukov, M.A. Sokolov, Radiation embrittlement of nuclear reactor pressure vessels steels: an international review, ASTM STP 1170, 1 (1993) 374.

[17] P. Petrequin, P. Soulat, B. Houssin, Effect of residual elements and Nickel on the sensitivity to irradiation embrittlement of SA 508 CL.3 pressure vessel steel and weld, Proceedings of the Irradiation embrittelment Thermal annealing and surveillance of reactor pressure vessels, Irradiation embrittelment Thermal annealing and surveillance of reactor pressure vessels (IAEA), 79 (1979) $195-200$

[18] R. Stofanak, T. Poskie, Y. Li, G. Wire, Irradiation damage behaviour of low alloy steel wrought and weld materials, 6th International Symposium on environmental degradation of materials in nuclear power systems - Water Reactors, August 1 - 5, San Diego, California (USA), 1993, 757 - 763.

[19] A. Nikolaeva, Y. Nikolaev, A. Krjoikov, The contribution of grain boundary effects to low - alloy steel irradiation embrittlement, Journal of Nuclear Materials. 218 (1994) 85-93.

[20] SA - 533/SA - 533M, Specification for pressure vessels plates, alloy steel, quenched and tempered manganese Molybdenum and Manganese - Molybdenum - Nickel, ASME B\&PV II Section A, American Society of Mechanical Engineers publications, New York, 2013.

[21] SA - 508/SA - 508M, Specification for quenched and tempered vacuum - treated carbon and alloy steel forgings for pressure vessels, ASME B\&PV II Section A, American Society of Mechanical Engineers publications, New York, 2013.

[22] KTA 3201.1, Components of the reactor coolant pressure boundary of light water reactors, part 1: materials and product forms, Nuclear Safety Standards Commission (KTA), Germany, 1998.

[23] RCC - MR, Design and construction rules for mechanical components of nuclear installations applicable for high temperature structures and ITER vacuum vessel, AFCEN publications, Paris, 2007. 